\title{
O REGISTRO DOCUMENTAL PSICOLÓGICO SOBRE A ÓTICA DA BIOÉTICA
}

Cláudio Vieira de LIMA ${ }^{1}$

\begin{abstract}
${ }^{1}$ Psicólogo. Docente do Curso de Odontologia da Universidade Vale do Rio Verde - UninCor, campus Belo Horizonte. E-mail: prof.claudio.lima@unincor.edu.br
\end{abstract}

Recebido em: 19/12/2016 - Aprovado em: 05/05/2017 - Disponibilizado em: 01/07/2017

\begin{abstract}
RESUMO: A psicologia tem cada vez mais buscado aprimorar seus procedimentos de avaliação e intervenção em diversos contextos, porém tem deixado uma lacuna quando o assunto é o registro dessas informações sobre seu cliente. São poucas as diretrizes ou discussões acerca desse tema, o que gera uma falta de modelos comuns de registro, tendo apenas o instrumento para registro o prontuário do paciente como consenso. Prontuário é um documento único e individual, constituído de um conjunto de informações geradas a partir de fatos, acontecimentos e situações sobre a saúde do paciente e a assistência a ele prestada. A garantia da preservação das informações, além de uma obrigação legal contida no Código Penal, no Código Civil e na maioria dos Códigos de Ética Profissional, é um dever prima facie de todos os profissionais e também das instituições.

Palavras chave: Registro Profissional; Psicologia; Bioética.
\end{abstract}

\section{THE PSYCHOLOGICAL DOCUMENTARY REGISTRY ON THE OPTICS OF BIOETHICS}

\begin{abstract}
Psychology has increasingly sought to improve its assessment and intervention procedures in various contexts, but it has left a gap when it comes to recording this information about its client. There are few guidelines or discussions about this topic which generates a lack of common registration models, having only the instrument for recording, the patient's chart, as a consensus. Record and a single and individual document, consisting of a set of information generated from facts, events and situations on the health of the patient and the care provided. The guarantee of the preservation of information, as well as a legal obligation contained in the Criminal Code, the Civil Code and most Professional Codes of Ethics, is a prima facie duty of all professionals and also of institutions.

keywords: Professional Registry; Psychology; Bioethics.
\end{abstract}

\section{INTRODUÇÃO}

A psicologia tem aprimorado, cada vez mais, seus procedimentos de avaliação e intervenção em diversos contextos, porém tem deixado uma lacuna bastante expressiva quando o assunto é o registro dessas informações sobre seu cliente. São poucas as diretrizes ou discussões acerca desse tema, o que gera uma falta de modelos comuns de registro, tendo apenas o prontuário como instrumento de registro do paciente como consenso.
Apesar disso, o registro em prontuário é de extrema importância, uma vez que possibilita o planejamento de uma intervenção adequada a partir do histórico de atendimento, independente do profissional que esteja acompanhando aquela pessoa. Outro ponto relevante está na possibilidade do uso desse documento como fonte importante de informações para pesquisas e coleta de dados. Dessa forma, além do respaldo ao profissional, o registro também é considerado um benefício ao cliente que pode acessar suas 
informações e ter um atendimento de qualidade.

Verifica-se que o registro em prontuários ou documentos com a mesma finalidade deve ser utilizado pelo psicólogo nas mais diversas áreas e contextos de atuação, como na clínica, na saúde e no hospital, na área jurídica, na escola, etc. (APA, 2007; CFP, 2009).

De acordo com a Resolução do CFP $n^{\circ}$ 01/2009, o registro documental decorrente da prestação de serviços psicológicos é obrigatório. Tal Resolução prevê que o registro documental em papel ou informatizado tem caráter sigiloso e constituise de um conjunto de informações que tem por objetivo contemplar de forma sucinta o trabalho prestado, a descrição e a evolução do caso e os procedimentos técnico-científicos adotados Esse registro deverá ser mantido permanentemente atualizado e organizado pelo profissional que acompanha o procedimento e em local que garanta sigilo e privacidade.

Mesquita e Deslandes (2010) sugerem que uma das barreiras relacionadas a anotações documentais por parte dos psicólogos pode estar ligada ao conteúdo e a questões éticas. Ainda de acordo com tais autoras, existe uma dificuldade em registrar eventos privados e questões da vida pessoal do cliente sem ferir o sigilo indicado no código de ética (CFP, 2005). Porém, ao se omitir o registro ou utilizar jargões técnicos que dificultem o entendimento de outra classe profissional, corre-se o risco de negligenciar informações importantes e necessárias para que outros profissionais possam alcançar o objetivo do tratamento. Esse ponto é relevante já que atualmente utiliza-se por base o modelo biopsicossocial de atuação, visando o atendimento da saúde de forma integrada (BARLETTA, 2008). Nesse sentido, é muito importante que os psicólogos estejam familiarizados com as questões éticas e legais que envolvem o registro e a documentação da atuação profissional, para que possam ter mais condições de decisão sobre o que escrever no prontuário (APA, 2007).

\section{REVISÃO DE LITERATURA}

\section{Prontuário Psicológico e registro de documentos}

Para Carneiro (2002, p. 834) Prontuário e um documento único e individual, constituído de um conjunto de informações geradas a partir de fatos, acontecimentos e situações sobre a saúde do paciente e a assistência a ele prestada. Tem caráter legal e sigiloso, possibilitando o a comunicação entre os integrantes da equipe e o registro de suas considerações técnicas. É preenchido e compartilhado por todos os técnicos da instituição. O prontuário é o documento de registro utilizado por toda a equipe que atende o paciente, nos casos de atendimentos multidisciplinar e o paciente 
tem direito a solicitar cópia deste documento. (CARNEIRO, 2002)

Nos casos de prestação de serviço psicológico apenas pelo profissional psicólogo, sem a participação de demais profissionais da saúde, ou seja, sem caracterizar o atendimento multidisciplinar, o profissional poderá realizar o registro documental. Esse registro é de uso do psicólogo, sendo considerado material sigiloso e privativo, pois pode conter informações sigilosas, hipóteses diagnósticas, bem como impressões do psicólogo sobre o atendimento. Nesse caso, o psicólogo não pode fornecer esses registros a terceiros, nem mesmo ao paciente, respeitando desta forma $o$ previsto no Código de Ética Profissional do Psicólogo

Conforme a Resolução CFP $\mathrm{N}^{\circ}$ 001/2009, que dispõe sobre a obrigatoriedade do registro documental decorrente da prestação de serviços psicológicos, o psicólogo fica obrigado a fazer o registro documental sobre a prestação de serviços psicológicos que não puder ser mantido prioritariamente sob a forma de prontuário psicológico, por razões que envolvam a restrição do compartilhamento de informações com o usuário e/ou beneficiário do serviço prestado.

Esse registro documental pode ser realizado em papel ou informatizado e tem caráter sigiloso. Constitui o registro um conjunto de informações que tem por objetivo contemplar de forma sucinta o trabalho prestado, a descrição e a evolução da atividade e os procedimentos técnicocientíficos adotados.

O psicólogo deve manter permanentemente atualizado e organizado o registro do procedimento.

Segundo Azevedo (2002) os documentos agrupados nos registros do trabalho realizado devem contemplar: identificação do usuário/instituição; avaliação de demanda e definição de objetivos do trabalho; registro da evolução do trabalho, de modo a permitir o conhecimento do mesmo e seu acompanhamento, bem como os procedimentos técnico-científicos adotados; registro de Encaminhamento ou Encerramento; documentos resultantes da aplicação de instrumentos de avaliação psicológica deverão ser arquivados em pasta de acesso exclusivo do psicólogo.

\section{Bioética}

O termo bioética foi criado no ano de 1970 pelo professor, biólogo e oncologista Van Resselaer Potter, que tinha como objetivo integrar os diferentes aspectos das ciências naturais com as ciências humanas por meio da ética, a fim de discutir as questões relacionadas a sobrevivência da humanidade diante dos desafios propostos entre os aspectos ecológico e tecnológico. (SILVA, 2007). 
Segundo Clotet (2005), a bioética não possui novos princípios éticos fundamentais. Trata-se da ética estudada na história da filosofia, mas aplicada a novas situações devido ao progresso científico no âmbito da saúde. Faz-se necessário destacar a importância do consentimento informado no desenvolvimento de pesquisas com seres humanos, apelando para o aperfeiçoamento deste na teoria e na prática.

No âmbito da saúde, a bioética se refere às questões relacionadas à vida, à relação profissional-paciente e em relação à pesquisa com seres humanos. Além disso, aborda a ética das questões sociais e dos problemas ambientais. Desse modo, existem princípios básicos da bioética que devem nortear a assistência e a pesquisa do profissional da saúde diante das questões da vida humana: beneficência, não-maleficência, autonomia e justiça (CLOTET, FEIJÓ \& OLIVEIRA, 2005).

\section{Bioética e informação}

As informações que os pacientes fornecem, quando de seu atendimento em um hospital, posto de saúde ou consultório privado, assim como os resultados de exames e procedimentos realizados com finalidade diagnóstica ou terapêutica, são de sua propriedade.

A garantia da preservação das informações, além de uma obrigação legal contida no Código Penal, no Código Civil e na maioria dos Códigos de Ética Profissional, é um dever prima facie de todos os profissionais e também das instituições. A preservação da informação pode ser abordada tanto pela questão da privacidade quanto pela da confidencialidade. A privacidade é a limitação do acesso às informações de uma dada pessoa, ao acesso à própria pessoa, à sua intimidade, é a garantia à preservação do seu anonimato, do seu resguardo, afastamento ou solidão. É a liberdade que o paciente tem de não ser observado sem autorização. $\mathrm{O}$ artigo XII da Declaração Universal dos Direitos Humanos, proposta pela ONU em 1948, já estabelecia o direito a não interferência na vida privada, pessoal ou familiar. A confidencialidade é a garantia do resguardo das informações dadas pessoalmente em confiança e a proteção contra a sua revelação não autorizada. O Juramento de Hipócrates já afirmava: "qualquer coisa que eu veja ou ouça, profissional ou privadamente, que deva não ser divulgada, eu conservarei em segredo e contarei a ninguém". O direito à privacidade não se extingue com a morte da pessoa. $O$ dever de confidencialidade que todos os profissionais de saúde devem observar se mantém mesmo após a morte do paciente.

O sigilo profissional na área da saúde visa garantir que o paciente, confiante no compromisso do sigilo, possa se sentir seguro em compartilhar com o profissional, informações de sua intimidade, pertinentes ao diagnóstico e correta indicação de tratamento. 
Tais informações, se tornadas públicas, poderiam trazer para o paciente algum tipo de constrangimento ou mesmo dano moral ou social.

Algumas escolas deontológicas defendem uma concepção desse segredo como um dever inviolável, absoluto. Assim entendido, em hipótese alguma o segredo poderia ser violado. Outras, que consideram que o sigilo confere ao profissional da saúde um excessivo poder, defendem a sua plena abolição. Na escola d

\section{Solicitação de informações do registro de documentos}

Conforme o Art. $21^{\circ}$ do Código de Ética dos Psicólogos (Resolução CFP 002/87 - É dever do psicólogo respeitar o sigilo profissional a fim de proteger, por meio da confidencialidade, a intimidade das pessoas, grupos ou organizações a que tenha acesso no exercício profissional.

No caso do psicólogo realizar o registro documental e o paciente solicitar o prontuário, cabe ao profissional esclarecer ao paciente sobre a diferença entre o registro documental e o prontuário e elaborar um laudo/relatório referente ao atendimento deste paciente, conforme disposto no Código de Ética Profissional do Psicólogo.

\section{DISCUSSÃO}

A formação do psicólogo necessita ampliar-se para a discussão das questões éticas relacionadas à saúde e integrar-se no posicionamento dos aspectos psicossociais que envolvem este âmbito (CASTRO \& BORNHOLD, 2004).

Dessa forma, Gioia-Martins e Rocha (2001) salientam a importância do currículo acadêmico do psicólogo caminhar rumo à responsabilidade social e compromisso com a ética.

O psicólogo não é preparado para elaboração e conservação de dados de seus clientes em seus consultórios particulares. Outra questão importante sobre à elaboração de documentos, refere-se à manutenção e quebra de sigilo. Ao emitir um documento, o psicólogo deve refletir sobre a demanda do documento, estabelecendo quais informações são pertinentes, inserindo apenas informações relevantes sobre a situação. A quebra de sigilo pode ocorrer nas situações em que se configure a busca do menor prejuízo, atendendo desta forma o previsto no Código de Ética Profissional do Psicólogo.

Nas situações em que se configure conflito entre as exigências decorrentes do disposto no Art. $27^{\circ}$ do CFP 002/87 e as afirmações dos princípios fundamentais desse Código, excetuando-se os casos previstos em lei, o psicólogo poderá decidir pela quebra de sigilo, baseando sua decisão na busca do menor prejuízo. Considerar-se-á assim o princípio da não maleficência. 


\section{CONSIDERAÇÕES FINAIS}

O prontuário ou o registro documental é um instrumento fundamental na prática do psicólogo, tanto para pesquisa como para a intervenção. $\mathrm{O}$ registro de sua atuação é necessário para que haja maior comunicação entre os profissionais e favoreça uma intervenção mais precisa e adequada. Porém, seu uso por psicólogos ainda ocorre de forma precária. Pode-se atribuir essa forma precária ao não conhecimento por parte dos profissionais das normas e legislação que regulamentam o procedimento.

Para tanto, a bioética necessita estar presente na formação e compromisso social do psicólogo da saúde. Dessa forma, faz-se necessário a busca da promoção da saúde e o fortalecimento do respeito ao indivíduo nas intervenções psicológicas e contribuições científicas no âmbito da saúde.

\section{REFERÊNCIAS}

ALMEIDA, F. F.; CANTAL, C. \& COSTA JUNIOR, A. L. C.. Prontuário psicológico orientado para o problema: um modelo em construção. Psicologia: Ciência e Profissão, 28(2),430-442. 2008.

AZEVEDO, F. M., THOMAS, C. V.. Registro psicológico em prontuário. Revista da Sociedade Brasileira de Psicologia Hospitalar. 2002.

CARNEIRO, Mauro Brandão et al. Documentação médica: guarda e manuseio dos prontuários médicos. Revista Sociedade de Cardiologia do Estado de São Paulo, v. 12, n. 6, nov. / dez., 2002.
CLOTET, J.. Bioética: uma aproximação. Joaquim Clotet (Org.) Porto Alegre: EDIPUCRS, 2003.

CLOTET, J., FEIJÓ, A. \& OLIVEIRA, M.. Bioética: uma visão panorâmica. Porto Alegre: EDIPUCRS, 2005.

Conselho Federal de Psicologia. Código de ética profissional do psicólogo (XII Plenário do conselho Federal de Psicologia). Brasília, DF, 2005.

\section{DUARTE, A. La dimensión ética en la} investigación psicológica. Revista Del Instituto de Investigaciones de la Facultad de Psicología. UBA. 5(1), 41-61, 2000.

FABBRO, L.. Limitações jurídicas à autonomia do paciente. Bioética. (CFM): http://www.portalmedico.org.br/revist a/bio1v7/limjuridicas.htm. 1999.

GOBBETTI, G.J., COHEN, C. Bioética: desenvolvimento humano e os profissionais de saúde. In: S.M.C. Ismael (Org.). Temas de prevenção, ensino e pesquisa que permeiam o contexto hospitalar. (pp. 149-162). São Paulo, 2005.

GOLDIM, J.. Psicoterapias e Bioética. In:

A.V. Cordioli (Org.). Psicoterapias: abordagens atuais. (pp. 119-133). Porto Alegre: Artes Médicas, 1998.

KLUCK, M.;GUIMARÃES, J. R. Questões éticas e legais do prontuário do paciente: da teoria à prática. Trabalho apresentado no VIII CBIS - Congresso da Sociedade Brasileira de Informática em Saúde, Natal - RN, 2002.

LEONE, S.; PRIVITERA, S.; CUNHA, J.T. (Coords.). Dicionário de Bioética. Editorial Perpétuo Socorro/Santuário, 2001.

MESQUISTA, A.M.O.; DESLANDES, S. F. A construção dos prontuários como expressão da prática dos profissionais de saúde. Saúde e Sociedade, 19(3),664-673, 2010 . 
NASCIMENTO, A. L., ANDRADE, M. G., ASSED, A. M. P.; BRASIL, M. A. A. Um modelo para o parecer psiquiátrico no hospital geral. Jornal Brasileiro de Psiquiatria, 55(2), 102-107, 2006.

RAMOS, D.L.P. Bioética: pessoa e vida. São Caetano do Sul: Difusão, 2009. 374p.

JUNQUEIRA, C. R. Bioética: conceito, contexto cultural, fundamento e princípios. In: RAMOS, D.L.P. Bioética e ética profissional. Rio de Janeiro uanabaraKoogan, 2007, p. 22-34.

SILVA, F. G. \& TAVARES-NETO, J. Avaliação dos prontuários médicos de hospitais de ensino do Brasil. Revista Brasileira de Educação Médica, 2007.

SOUZA, M. P.R. Prontuários revelando os bastidores do atendimento psicológico à queixa escolar. Estilos da Clínica, X (18), 2005. 